For cytological study, fresh pycnia of the white pine blister rust were fertilised by interchanging the pycniospores, and, after a period of 48 hours, were fixed in Flemming's weaker solution together with an equal number of unfertilised pycnia of similar age. A copious exudate of nectar containing pycniospores was present on both sets of pycnia. Sections of both fertile and infertile pycnia were made as thin as $3 u$ and stained with a modification of the triple stain. Both contained a few of the filamentous hyphæ described above, but in the fertile preparations eleven cases of pycniospores fusing with these hyphæ have been observed, while no case of fusion was found in the sterile preparations. These fusions are similar to the unions recently reported by $\mathrm{Craigie}^{3}$ for the sunflower rust.

The pycniospores were united to the ends of the hyphæ by short tubes that were longer and of a somewhat smaller diameter than those illustrated by Craigie $^{3}$. A few of the pycniospores seemed to be empty while others contained nuclei in the usual position. Actual migration of nuclei through the short connecting tubes has not been observed. Whether these tubes are extensions of the filamentous hyphæ or germ tubes sent out by the pycniospores remains to be established. A more detailed account covering the investigations undertaken on this subject will be presented at a later date.

School of Forestry, Royale K. Puerson.

University of Idaho. March 28.

"Arthur, C. J., "The Plant Rusts", 1-446, 1929.

2 Colley, R. H., "Parasitism, Morphology, and Cytology of Cronartium ribicola", J. Agric. Res., 15, 619-659; 1918.

${ }^{3}$ Craigie, J. H., "Union of Pycniospores and Haploid Hyphæ in Puccinia helianthi Schw.", NATrike, 131, 25, Jan. 7, 1933.

\section{Lignin Content of Cellulose Products}

IN the working out of a new method of determination of cellulose, especially suitable for cereal straws, we have recently had occasion to determine the lignin contents of cellulose products obtained by various means. Chlorinations, either gaseous or in solution (as our new method involves) were continued until there was no trace of a characteristic red colour on the subsequent addition of sodium sulphite. In spite of this, however, the lignin contents of the products from a number of straws were, in general, between $2 \cdot 5$ and $3 \cdot 0$ per cent.

The lignin determination depends on the resistance of lignin, first to cold 72 per cent sulphuric acid, and later to boiling with more dilute acid. Pure cellulose under such conditions yields only a trace of apparent lignin, no doubt due to slight charring or caramelisation. Starch and glucose similarly yield only a trace of apparent lignin. A pentose sugar, on the other hand, gave with this treatment an appreciable quantity of some material as resistant as lignin and determined as such in the accepted methods.

Natural celluloses from woods and straws are known to consist of 'true' cellulose associated with other polysaccharide material, known as 'cellulosans'. It seemed possible, therefore, that the lignin found in straw celluloses might be apparent rather than real, and be in truth derived secondarily by the action of the sulphuric acid, on the 'cellulosan' or pentosan fraction of the natural cellulose. Accordingly, by mild hydrolysis with 5 per cent acid for I hour, this fraction was largely removed. The apparent lignin content of the residues fell by $25-30$ per cent in every case, indicating the correctness of this view. However, the residual lignin contents were even then much greater than the figures obtained on most wood celluloses, and, moreover, could not be reduced by gross over-chlorination and repeated sulphite extractions. We are, therefore, of the opinion that, while a part of the apparent lignin content of celluloses from cereal straws is secondarily produced from the cellulosan fraction, there is nevertheless a portion of true lignin (or some other acidresistant material) very tenaciously retained by the cellulose itself and possibly in combination. We shall investigate this point further in an attempt to characterise or extract this small residual fraction.

In view of this observation that apparent lignin may be formed from the pentose grouping, we consider that the whole question of the determination of lignin by the 72 per cent sulphuric acid method must be critically re-examined. The results usually given for straws and hardwoods will probably be found to be too high. Those for softwoods, in view of the smaller content of pentose material, are probably much more nearly accurate. By submitting straws to an acid pre-treatment (5 per cent sulphuric acid for 1 hour) before the determination of lignin and removing thereby the major part of the pentose material present both as polyuronide hemicellulose and as cellulosan, the apparent lignin content was lowered by 25 per cent or more. It seems likely that this lower figure is the true value.

A. G. Norman.

S. H. JENKINS.

Fermentation Department,

Rothamsted Experimental Station, Harpenden, Herts.

${ }^{1}$ Hawley and Norman, Ind. and Eng. Chem., 24, 1190; 1932.

\section{Whale Shark in the Waters Around Ceylon}

Wrixh reference to Dr. Gudger's letter ${ }^{1}$ on the above subject, I am inclined to agree with the view which his last paragraph implicates, namely, that Rhineodon typus is a rare visitant to the waters around Ceylon.

During a residence of nearly twenty-three years in Ceylon, I have neither seen a whale shark nor have I heard of one having been washed ashore. It seems scarcely likely that this shark, with its great size and peculiar characters, could have escaped the notice of the fishermen.

This negative evidence, however, is not altogether convincing. I am reminded of the occurrence of whales in South Indian waters. After considerable experience of marine biological surveying in the seas around Ceylon, I should have been prepared to say that although whales are occasionally seen they are relatively rare and could certainly not be fished profitably for commercial purposes; yet a whaling expert, who came to Ceylon two years ago with the intention of establishing a whaling station in Ceylon, assured me that whales were more common than I had supposed and that commercial whaling off the eoast of Ceylon could be carried on successfully.

It is possible, therefore, that the giant shark Rhineodon typus may be more common in South Indian waters than the small number of reliable records would lead us to believe.

Colombo Museum, Ceylon.

Joseph Pearson.

${ }^{1}$ NATURE, 131, 165, Feb. 4, 1933. 